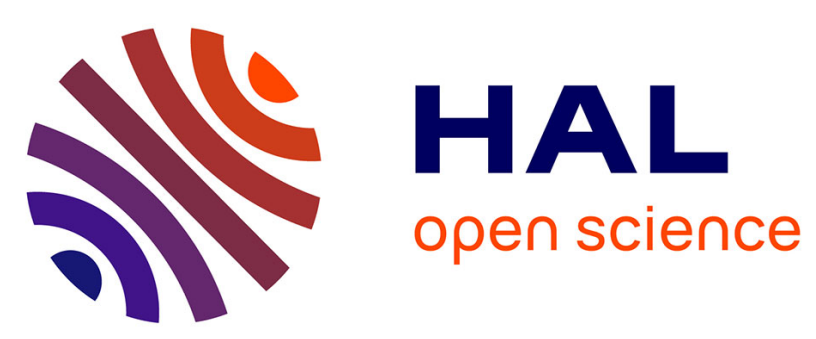

\title{
Oscillatory activity of the human cerebellum: The intracranial electrocerebellogram revisited.
}

\author{
Sarang S. Dalal, Daria Osipova, Olivier Bertrand, Karim Jerbi
}

\section{To cite this version:}

Sarang S. Dalal, Daria Osipova, Olivier Bertrand, Karim Jerbi. Oscillatory activity of the human cerebellum: The intracranial electrocerebellogram revisited.: Intracranial EEG of the human cerebellum. Neuroscience and Biobehavioral Reviews, 2013, 37 (4), pp.585-93. 10.1016/j.neubiorev.2013.02.006 . inserm-00790063v2

\section{HAL Id: inserm-00790063 https://www.hal.inserm.fr/inserm-00790063v2}

Submitted on 18 May 2013

HAL is a multi-disciplinary open access archive for the deposit and dissemination of scientific research documents, whether they are published or not. The documents may come from teaching and research institutions in France or abroad, or from public or private research centers.
L'archive ouverte pluridisciplinaire HAL, est destinée au dépôt et à la diffusion de documents scientifiques de niveau recherche, publiés ou non, émanant des établissements d'enseignement et de recherche français ou étrangers, des laboratoires publics ou privés. 


\title{
Oscillatory activity of the human cerebellum: The intracranial electrocerebellogram revisited
}

\author{
Sarang S. Dalal ${ }^{\mathrm{a}, *}$, Daria Osipova ${ }^{\mathrm{b}}$, Olivier Bertrand ${ }^{\mathrm{c}}$, Karim Jerbi $^{\mathrm{c}}$ \\ ${ }^{a}$ Zukunftskolleg \& Department of Psychology, University of Konstanz, Germany \\ ${ }^{b}$ Donders Institute for Brain, Cognition and Behaviour, Radboud University Nijmegen, Netherlands \\ ${ }^{c}$ INSERM U1028, CNRS UMR5292, Lyon Neuroscience Research Center, Brain Dynamics and Cognition Team, Lyon, France
}

\begin{abstract}
The functional electrophysiology of the human cerebellum remains poorly characterized. Existing knowledge originates primarily from lesion studies and increasingly from hemodynamic measures such as functional magnetic resonance imaging, along with some evidence in recent years from transcranial magnetic stimulation.

In this context, we revisit the few existing records of intracranial recordings from the human cerebellum, and uncover additional little-known reports - three from the Soviet Union, published in Russian between 1949-1951, and one from Belgium, published in French in 1964. These studies together demonstrate electrical rhythms of the human cerebellar cortex at frequencies as high as $250 \mathrm{~Hz}$, including task-related modulations. A reanalysis of their electrode traces with state-of-the-art spectral analysis techniques confirm the reported frequency bands, and showed that these modulations were sustained for 100-200 ms. These remarkable observations from the early ages of intracranial mapping of the human brain are in line with recent electrophysiological studies of oscillations in the rodent cerebellum as well as magnetoencephalographic findings in humans.

Time-frequency analyses have provided valuable insight into the function of cerebral cortex, and may prove even more critical for the differing neurophysiology of the cerebellum. We contend that these insights will be invaluable to bridge the role of oscillatory networks in the cerebellum with those of cerebral cortex in mediating perception, action, and cognition and to investigate possible cerebellar involvement in neurological dysfunction.
\end{abstract}

\section{Highlights}

- The functional electrophysiology and spectral profile of the human cerebellum remains unclear

- Recent animal LFP literature demonstrate the cerebellum produces high frequency oscillations

- We review the exceptionally rare reports of intracranial EEG from the human cerebellum

- Previously uncited studies in French and Russian demonstrate task-related oscillatory modulations up to $250 \mathrm{~Hz}$

- We discuss implications for noninvasive detection of cerebellar oscillations with MEG and EEG

Keywords: Cerebellum, Intracranial electroencephalography, Electrocorticography, High-frequency oscillations, Gamma band activity, Magnetoencephalography

\section{Running title: Intracranial EEG of the human cerebellum}

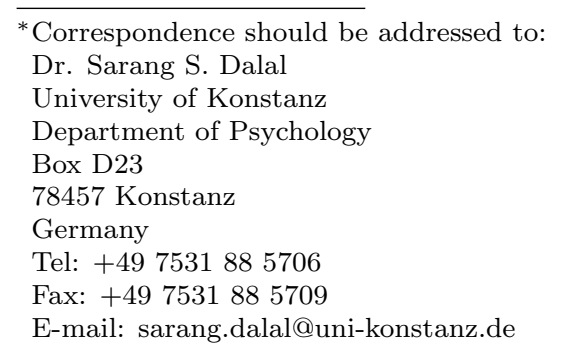




\section{Introduction}

The electrophysiology of the human cerebellum remains largely unexplored compared to cerebral cortex. A prevailing corticocentric view of brain function (Parvizi, 2009) may partially explain this bias, and it additionally remains unclear whether and how the cerebellum can be reliably accessed with noninvasive measures such as EEG and MEG (Niedermeyer and da Silva, 2005). While PET and fMRI have had access to cerebellar hemodynamics (for a review, see Stoodley and Schmahmann, 2009), their relationship to underlying neural activity is still under investigation. As in cerebral cortex, only certain types of neural assemblies may be correlated with a significant hemodynamic response in the cerebellum (for a review, see Diedrichsen et al., 2010).

Although the cerebellum has been classically represented as a facilitator of motor function, mounting evidence indicates a far more diverse role of the cerebellum (Strick et al., 2009; Glickstein et al., 2011), and it therefore follows that cerebellar pathology may play a more significant role in neurological disorders than previously thought (Grimaldi and Manto, 2012). Furthermore, cerebellar abnormalities are suspected to be involved in some psychiatric disorders (Schmahmann et al., 2007).

To our knowledge, only two scalp EEG reports of cerebellum activity exist (Muthukumaraswamy et al., 2003; Lascano et al., in press), though a small body of MEG literature has accumulated. These MEG activations took the form of evoked fields (Jousmäki et al., 1996; Tesche and Karhu, 1997; Hashimoto et al., 2003; Ioannides and Fenwick, 2005; Ioannides et al., 2005; Martin et al., 2006; Tesche et al., 2007; Houck et al., 2007), connectivity with cerebral cortex (Gross et al., 2002; Tass et al., 2003; Timmermann et al., 2004; Pollok et al., 2005; Jerbi et al., 2007; Pollok et al., 2007; Belardinelli et al., 2007; Kujala et al., 2007; Cornwell et al., 2007; Krause et al., 2010; Wibral et al., 2011), spectral modulations (Tesche and Karhu, 2000; Muthukumaraswamy et al., 2006; Guggisberg et al., 2007; Dalal et al., 2008; Wilson et al., 2010; Guggisberg et al., 2011; Kennedy et al., 2011; Fujioka et al., 2012), or coupling with observed hand kinematics (Bourguignon et al., 2013). A recent study found that cerebellar resting state activity derived from fMRI correlated well with beta-band MEG activity that also localized to cerebellum (Brookes et al., 2011). In several of these cases, the cerebellum activations appear to be serendipitous and were not investigated in detail. Pathological cerebellum activity has also been reported using MEG, related to Parkinsonian resting tremor (Timmermann et al., 2003), dystonia (Butz et al., 2006), essential tremor (Schnitzler et al., 2009), early onset psychosis (Wilson et al., 2009, 2011), and epilepsy (Kotini et al., 2010; Mohamed et al., 2011).

Intracranial EEG from neurosurgery patients has helped to elucidate the neurophysiology of cerebral cortex and structures such as the hippocampus (e.g., Axmacher et al., 2008) and basal ganglia (e.g., Lalo et al.,
2008). However, the cerebellum is a less common neurosurgical target, and furthermore, a protocol for clinical use of cerebellum recordings has never been firmly established. Therefore, reports of direct cerebellum recordings have been exceedingly rare.

In the past decade, electrophysiological analyses at the level of both local field potentials (LFP) and scalp EEG/MEG have come to embrace both frequencydependent connectivity measures and higher frequency information revealed by time-frequency analyses. Intracranial EEG, typically recorded from epilepsy or brain tumor patients, have been able to provide similar evidence of high frequency content in human cerebral cortex (e.g., Crone et al., 1998; Axmacher et al., 2008; Edwards et al., 2009; Jacobs et al., 2010; Vidal et al., 2010; Chang et al., 2011; Ossandón et al., 2012). (See Jensen et al. (2007), Crone et al. (2011), and Worrell et al. (2012) for overviews.) Similar examination of the cerebellum has come only more recently, with LFP data from the rodent cerebellum revealing rich information content in the $30-200 \mathrm{~Hz}$ regime (de Zeeuw et al., 2008; de Solages et al., 2008; Middleton et al., 2008). Middleton et al. (2008) additionally found corresponding activity in human cerebellum tissue slices in vitro.

In this article, we shall revisit the few human intracranial cerebellum reports known to exist. We focus in particular on three little known studies, all of which contribute to the evidence of task-related spectral modulations of cerebellum activity, especially in the higher frequency bands. Two of these studies have been virtually uncited in the English-language literature.

We shall contend that this higher frequency activity will likely be critical to uncovering cerebellar involvement in perception, action, and cognition in humans. Knowledge gained from intracranial EEG has been guiding efforts to improve noninvasive MEG/EEG techniques for characterization of high frequency activity originating from cerebral cortex. Similarly, we believe that these reports of intracranial EEG from the human cerebellum suggest that time-frequency approaches will be necessary for attempts to extract cerebellar activity from noninvasive MEG/EEG investigations in humans.

\subsection{Brief Overview of Cerebellum Electrophysiology}

It has been commonly speculated that the cerebellum may be inaccessible to EEG, and by extension to MEG, due to a combination of potential factors. Cerebellar LFP amplitudes are typically lower amplitude than corresponding recordings from cerebral cortex, and it was additionally speculated that a lack of sufficient synchrony across cerebellar neurons, or perhaps "closed field" geometry of Purkinje cells, could conspire to reduce scalp EEG/MEG amplitudes below detection threshold (Gerloff et al., 1996).

However, such speculation arose from an era when ongoing low-frequency oscillations and slow evoked potentials were en vogue; these potential explanations may have 


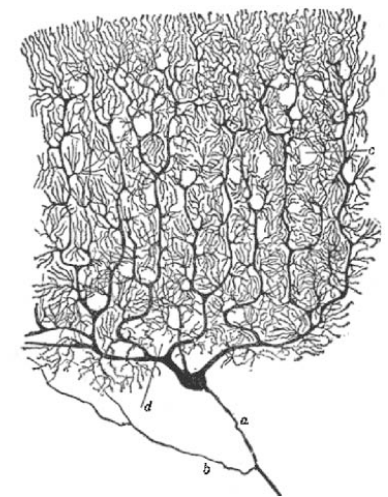

Figure 1: The classic illustration from Ramón y Cajal (1904) of a Golgi stain showing the dendritic arbor of cerebellar Purkinje cells. The dendrites are arranged in parallel, similar to the apical dendrites of pyramidal cells, and likely are the major contributors to externally recorded electromagnetic fields from the cerebellum.

arisen as neither of these phenomena were commonly observed in scalp recordings over cerebellar regions. Furthermore, the geometrical arrangement of Purkinje cells and parallel fibers in cerebellar cortex (Ramón y Cajal, 1904) is very analogous to pyramidal cells in cerebral cortex (see Figure 1), and cerebellar laminar recordings show that signals arising from the Purkinje and granule layers indeed produce characteristic potentials on the cerebellar surface (Eccles et al., 1966a,b; VanGilder et al., 1967; Nicholson and Llinas, 1971). Okada et al. (1987), in particular, demonstrated that Purkinje cells in the turtle cerebellum produce significant magnetic evoked fields. Finally, the cerebellum is sometimes regarded as a "deep" source, and while the anterior cerebellum is indeed quite a distance from the head surface, the posterior cerebellar cortex is nearly the same depth as the surface of the easily measurable occipital cortex. The possibility of recording these signals on the scalp surface with EEG and MEG, then, demands another look with modern analysis and recording techniques.

The earliest local field potential recordings from the animal cerebellum remarked on the lower-amplitude, higherfrequency nature of the spontaneous cerebellar signal, reporting dominant activity in the range of $150-250 \mathrm{~Hz}$ (Adrian, 1935), 155-210 Hz (Dow, 1938), and 170-230 Hz (ten Cate and Wiggers, 1942). Pellet (1967) later observed activity in the $200-400 \mathrm{~Hz}$ regime in the guinea pig. When it became possible to perform signal averaging relative to repeated events, event-related potentials (ERPs) derived from cerebellar LFP recordings generally exhibited latencies between 4 and 50 ms (Snider and Stowell, 1944; Fuchs and Kornhuber, 1969; Nicholson and Llinas, 1971; Kwan and Murphy, 1974a,b; Rowland and Jaeger, 2008). In contrast, ERPs of the longer latencies typical of cerebral cortex seem rare in the cerebellum.

Several decades passed by before these higher frequency rhythms in the cerebellum regained widespread attention, beginning with a "manifesto for synchrony" in these high frequencies across cerebellar populations (Isope et al., 2002). This review of the evidence for highfrequency cerebellar activity argued that they could facilitate precise timing of perception and action as well as provide a mechanism for information storage. Subsequently, de Solages et al. (2008) showed that the Purkinje cell layer in Wistar rats produces $200 \mathrm{~Hz}$ oscillations, which seem to entrain unit firing. High-frequency LFPs from the molecular and granule cell layers were observed but were far less pronounced, suggesting that recurrent inhibitory connections between Purkinje cells were the primary contributor. Middleton et al. (2008) found gamma (30-80 Hz) and what they termed "very fast oscillations" (80-160 Hz) in cerebellar tissue slices from mice and humans, with modulations effectuated by nicotine, gabazine, and quinine.

The dendritic physiology of cerebellar neurons differs markedly from that of pyramidal cells in cerebral cortex, and therefore, the cerebellum may primarily exhibit oscillatory modulations that are not necessarily phase-locked, precluding robust production of phase-locked evoked responses from natural stimuli. This would have given the impression that the cerebellum is silent to scalp EEG/MEG for several years until the more recent revival of non-phase-locked analyses using time-frequency techniques. If so, then such event-related power modulations may prove even more critical for understanding cerebellar physiology. Indeed, such time-frequency analyses have revealed more compelling MEG findings, including lowfrequency oscillations between 2 and $30 \mathrm{~Hz}$ (Tesche and Karhu, 2000; Gross et al., 2002; Tass et al., 2003; Pollok et al., 2005; Butz et al., 2006; Jerbi et al., 2007; Belardinelli et al., 2007; Kujala et al., 2007; Pollok et al., 2007; Wilson et al., 2010; Fujioka et al., 2012) and a higher frequency regime between approximately 60-150 Hz (Dalal et al., 2008; Guggisberg et al., 2007, 2011).

\subsection{Intracranial EEG of the Human Cerebellum}

Intracranial EEG in human patients has paved the way for the investigation of high-frequency activity in cerebral cortex (Lachaux et al., 2000; Crone et al., 1998), and provided validation for corresponding noninvasive findings from EEG and MEG (Hoogenboom et al., 2006; Ball et al., 2008; Dalal et al., 2008, 2009). However, invasive recordings of the human cerebellum are extremely rare, and only a handful of reports exist. Niedermeyer (2004) reviews the more well-known of these reports.

The very first report of intracranial EEG in humans, Foerster and Altenburger (1935), shows traces from various locations on the brain surface in neurosurgery patients, remarkably including one trace from the surface of cerebellar cortex. We will discuss this report in greater detail below.

Schwartz and Kerr (1940) subsequently published short examples of cerebellar surface recordings from two patients, one with Ménière's disease and the other with a cerebellar tumor. The shown traces, unfortunately, are 


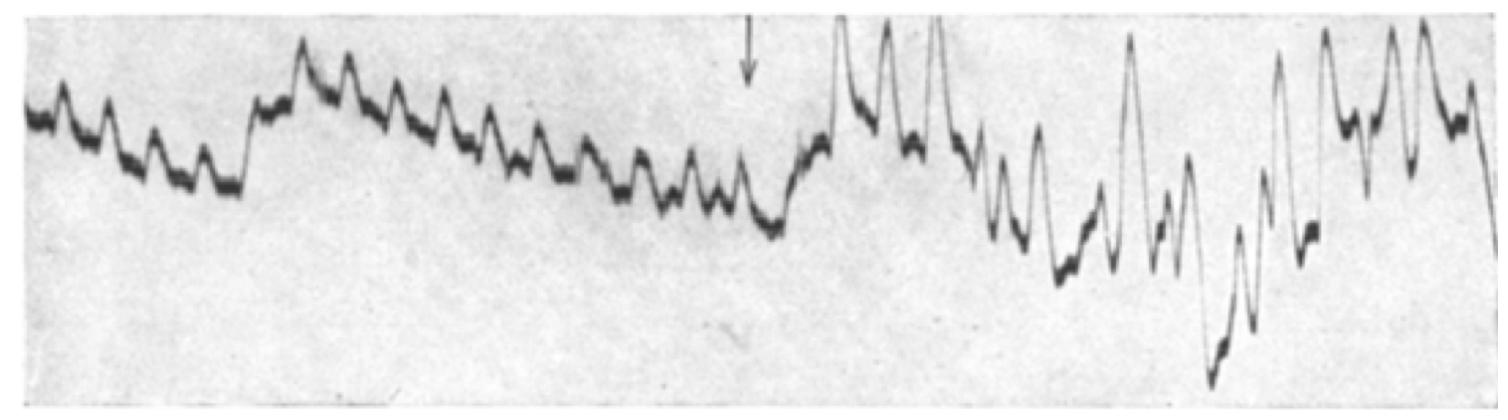

Figure 2: A recording from the right cerebellar hemisphere of a human patient, reproduced from Foerster and Altenburger (1935, Figure 10). The patient closed his right fist at the latency indicated by the arrow. Unfortunately, the timescale is unclear, though an increase in oscillatory power is quite evident.

difficult to interpret and discussed only briefly in the context of potential disease-related abnormalities.

The next well-known publications reported a series of ethically outrageous studies by Roger Heath that employed intracranial EEG with widespread coverage, including cerebellum, in exploratory experiments on a suicidal, drug-addicted, homosexual patient - he was given either cannabis to smoke or methamphetamine to inject (Heath, 1972a), and ultimately encouraged to have sexual relations with a female prostitute (Heath, 1972b), while being monitored with invasive electrodes. These publications show some cerebellum electrode traces, but otherwise, the cerebellum is not discussed in detail and no effects are readily apparent from the shown figures. A final report includes cerebellum recordings from a different patient obtained during various emotional states (Heath et al., 1974), with some spindle-like bursts apparently observed in correlation with fear or anger.

Niedermeyer and Uematsu (1974) observed lowfrequency oscillations $(4-10 \mathrm{~Hz})$ in three human LennoxGastaut syndrome patients implanted with cerebellar electrodes in an experimental attempt at stimulation therapy. These oscillations seemed to be attenuated during drowsiness before disappearing altogether during sleep, instead being replaced by sharp waves. Seizure activity in both cerebellar leads and scalp electrodes manifested at around $16 \mathrm{~Hz}$.

A more recent series of case studies from various groups describe cerebellar recordings for clinical diagnostics in pediatric patients with cerebellar tumors (Harvey et al., 1996; Delande et al., 2001; Chae et al., 2001; Mesiwala et al., 2002; Gupta et al., 2003; Koh et al., 2010; Yagyu et al., 2011; Lascano et al., in press). These recordings helped delineate tumor boundaries and explain clinical observations such as hemifacial seizures. Unfortunately none of these addressed the spectral characteristics of the signals nor had the opportunity to investigate cerebellar responses to controlled stimuli.

A few other overlooked reports of human cerebellum recordings exist. One paper by Sem-Jacobsen et al. (1955) describes cerebellar recordings from a Huntington's disease patient as "very flat and featureless" in an advanced stage Huntington's patient, while a presenile patient exhibits "more activity." An inspection of their figure show that electrodes from the presenile patient contain evident alpha band activity $(8-10 \mathrm{~Hz})$, while recordings from the advanced stage patient indeed show "flat" responses with occasional delta oscillations. It is unknown whether it would have been possible to observe higher frequencies with their equipment and amplifier settings, and in any case, the figure's time scale was not ideal for presenting higher frequency activity. The authors generally refrain from interpretation of their results since, "the general pattern or patterns of electrical activity in the cerebellum in man are not known." Unfortunately, the situation has little improved some 57 years later.

However, the nature of electrical activity in the human cerebellum was the direct focus of other papers that we uncovered, one in French (Rétif, 1964) and the others in Russian (Irger et al., 1949b,a, 1951). These reports seem to have gone largely unnoticed, perhaps due to journal availability, the language barrier, and perhaps even the Cold War. Yet, together with Foerster and Altenburger (1935), these papers display several segments of high-quality human cerebellum recordings under various conditions, meriting a reintroduction, translation, and reinterpretation of their results.

We contend that these reports importantly provide a foundation for more recent findings from noninvasive MEG experiments in humans as well as animal electrophysiology. In particular, they provide substantial further evidence of low- and high-frequency electrical activity originating from the human cerebellum, and that this activity is furthermore task-modulated. Therefore, rather than employing techniques designed to investagate time-locked evoked activity, time-frequency methods are likely to be more appropriate for analyzing cerebellar signals and may be key to their noninvasive detection with MEG and EEG in humans.

\section{Foerster and Altenburger, 1935 (Germany)}

Foerster and Altenburger (1935) described intraoperative electrocorticographic recordings performed in brain 
tumor and epilepsy patients, the first ever reported in humans. They observed various brain regions during both spontaneous activity as well as responses to simple tasks or stimuli. Of note for the present topic, they showed activity from an electrode placed on the exposed right cerebellar hemisphere in response to clenching of the right fist. A clear oscillatory modulation is observed relative to onset of the fist clench (Figure 2), though unfortunately the timescale of the trace and therefore the frequency of the oscillation are both unclear. It is also impossible to know in retrospect if this recording might have been contaminated by muscle activity or other technical problems.

Despite these disappointing shortcomings, this pioneering work had already suggested a potential role for modulations of oscillatory activity in cerebellar processing.

\section{Irger et al., 1949, 1951 (Soviet Union)}

Iosif Markovich Irger was the head of neurosurgery at the Moscow Clinic for Nervous Diseases, and authored a series of short articles describing cerebellar potentials recorded from patients.

According to these Russian-language reports, some electrodes were embedded in the occipital bone over the cerebellum under novocaine anesthesia, while others were implanted directly into the cerebellum intraoperatively with needle electrodes.They connected these electrodes to an ink-based Grass oscillograph for most recordings, switching to a cathode-ray oscilloscope to capture higher frequencies above $70 \mathrm{~Hz}$. Most recordings were performed with a bipolar montage.

Irger et al. (1949b) describes their earliest recordings from the human cerebellum. They describe two patient recordings in some detail. One patient had atrophy of the right cerebellar hemisphere after removal of an acoustic neuroma, and consequently demonstrated mostly alpha waves in the affected hemisphere. The second patient had a cyst and tumor in the left cerebellar hemisphere, which showed an overall reduction of electrical activity, while 40$50 \mathrm{~Hz}$ oscillations were principally observed in his apparently healthy right cerebellar hemisphere.

They classified a few different frequency bands of interest, in particular focusing on the $6-8 \mathrm{~Hz}, 30-50 \mathrm{~Hz}$, and 70-220 Hz bands. Remarkably, the authors show a cerebellar response to a visual flash stimulus recorded with the Grass oscillograph (Figure 3), with induced oscillations in the $30-50 \mathrm{~Hz}$ range. Unfortunately, it is unclear whether they were able to record stimulus timing with the oscilloscope, preventing analysis of stimulus-related changes for the highest frequency bands.

Since the signal quality of intracranial EEG allows reliable spectral analysis of single trials (e.g., Flinker et al., 2010) and real-time applications (e.g., Lachaux et al., 2007), we reexamined this visual response in further detail with multitaper spectral analysis (see Appendix for detailed methodology). This analysis confirmed the observation of an increase in activity centered around $40 \mathrm{~Hz}$, noted at approximately 650-950 ms post-stimulus (Figure 3). Additionally, an increase in power between 180$400 \mathrm{~ms}$ was revealed over a band of $10-25 \mathrm{~Hz}$, with some energy at $60 \mathrm{~Hz}$. Finally, an increase in the $80-100 \mathrm{~Hz}$ range, the presumed upper limit of the Grass EEG system, was noted near the end of the trace, between 1000 and $1300 \mathrm{~ms}$ post-stimulus.

The Soviet group followed up with another report the same year summarizing their findings in a total of 50 patients (Irger et al., 1949a), presumably all with cerebellar tumors, and found that tumors located in specific regions of the cerebellum lead to changes in the characteristics of spontaneous electrical activity. They reiterated their observation of the various frequency bands of the cerebellum, republishing their previous visual responses. Again, they emphasized that the fastest observed signals occurred at approximately $220 \mathrm{~Hz}$, showing another example of a spontaneous recording made with an oscilloscope.

A final report (Irger et al., 1951) describes a comparative study, contrasting cerebellar recordings from their patients with recordings made in rabbits, dogs, and pigeons, reiterating their finding of spontaneous activity as high as approximately $200 \mathrm{~Hz}$ across all species.

\section{Rétif, 1964 (Belgium)}

Jean Rétif, a neurosurgeon at the Université Libre de Bruxelles (Free University of Brussels), published a report in French describing another remarkable set of recordings from the human cerebellum (Rétif, 1964). These patients were undergoing resection of the spinothalamic tract or the motor root of the trigeminal nerve in the posterior fossa for the treatment of intractable pain. The target resection area was directly behind the cerebellum, but otherwise the patients were considered to have normal cerebellum function. Patients received light general anesthesia with fluothane.

The intracranial EEG was recorded on the cerebellar surface (posterior vermis, "approximately at the level of the pyramid or uvula") using $\mathrm{AgCl}$ electrodes (10$20 \mathrm{~mm}$ interelectrode distance) as well as at depth (inferior semilunar lobule, also known as crus II) using stainless steel electrodes (3 $\mathrm{mm}$ interelectrode distance, $1 \mathrm{~mm}$ diameter). The traces were monitored using an oscilloscope, allowing the observation of high-frequency activity.

Rétif generally observed that the dominant spontaneous rhythm from the surface of the cerebellum was approximately $200 \mathrm{~Hz}$, with an average amplitude of $10 \mu \mathrm{V}$, mixed with activity of about $150 \mathrm{~Hz}$ and occasional higheramplitude $75 \mathrm{~Hz}$ oscillations. Comparing with bipolar EEG on the scalp over parieto-occipital regions, he estimated that signals from cerebral cortex were 5 to 6 times stronger than those of cerebellar cortex.

He furthermore observed slightly higher frequencies of $220-250 \mathrm{~Hz}$ from cerebellar depth electrodes placed in crus II, with amplitudes of $25-30 \mu \mathrm{V}$, and noted that they 

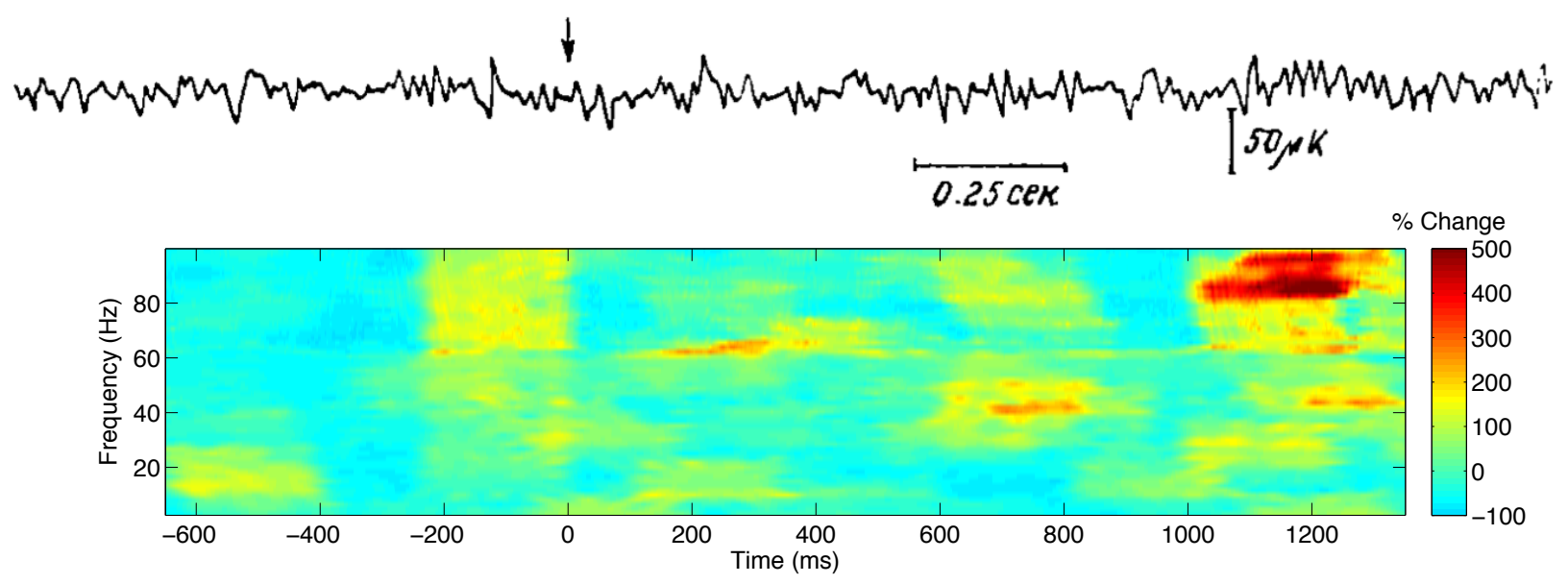

Figure 3: At top, a spontaneous recording from bipolar needle electrodes implanted in the skull over cerebellum, reproduced from Irger et al. (1949a, Figure 2b), with a visual flash stimulus presented at $\mathrm{t}=0$. At bottom, a spectrogram based on the digitized data is shown, expressed as the percentage change in power with respect to the prestimulus baseline period before $\mathrm{t}=0$. Between $180-400 \mathrm{~ms}$, increase in $10-25 \mathrm{~Hz}$ power was observed, while between $650-850 \mathrm{~ms}, 35-50 \mathrm{~Hz}$ activity was observed. A very late modulation, between $1000-1300 \mathrm{~ms}$, was observed in the $80-100 \mathrm{~Hz}$ band. Analysis of higher frequencies was not possible from this trace, recorded with an ink-based Grass oscillograph.

seemed to be modulated by underlying $10-12 \mathrm{~Hz}$ oscillations, foreseeing the current trend of phase-amplitude coupling in intracranial EEG analysis (Canolty et al., 2006; Osipova et al., 2008; Canolty and Knight, 2010). In these depth electrodes, Rétif additionally observed spike-like activity of a duration of approximately $1 \mathrm{~ms}$, which he speculated could correspond to the Purkinje cell and granule cell spikes described by Brookhart et al. (1950, 1951).

One possible task-related trace was shown (Figure 4). Rétif reports that the observed waveform was likely in response to a "fortuitous" sensory stimulation, which he was not able to specifically measure in a controlled fashion due to limitations of the recording apparatus. By his estimate, the induced oscillations had a frequency of approximately $200 \mathrm{~Hz}$.

We reexamined this recording using multitaper spectral analysis (Figure 4), with a procedure identical to that used for the Soviet data. Defining the first $50 \mathrm{~ms}$ of the trace as a baseline, a sustained power increase over the $200-300 \mathrm{~Hz}$ range is revealed, as well as more transient power increase in the 100-150 Hz range and another band centered around $60 \mathrm{~Hz}$ representing the large evident oscillations between 65-95 ms.

While it is frustrating that we cannot know the specific circumstances that induced the shown response, and whether such a response might be reproducible, these findings suggest that modulations in the higher frequency bands may be especially important in examining task- and stimulus-related cerebellar responses.

\section{Discussion}

These papers, in combination with recent research emerging from animal electrophysiology, support the case for task-related spectral modulations in the cerebellum, with a potentially large contribution from rather high frequencies up to approximately $300 \mathrm{~Hz}$.

de Zeeuw et al. (2008) gave an overview of the putative functional roles of cerebellar frequency bands examined in cerebellar LFP literature. They attributed the delta (1-4 Hz) and theta bands (4-9 Hz) to learning-dependent timing. Additional potential functions of the theta band include sensory state assessment and intermittent motor control; some MEG evidence supports this latter role in humans (Gross et al., 2002). Pathological tremors with approximately the same frequency appear to be associated with cerebellar and motor cortex oscillations at both the tremor frequency and its first harmonic (Timmermann et al., 2003; Schnitzler et al., 2009). The beta band (10$30 \mathrm{~Hz}$ ), meanwhile, appears to subserve connectivity with cerebral cortex during movements and sensorimotor processing, and human MEG experiments likewise support these roles (Pollok et al., 2007; Belardinelli et al., 2007). Notably, the authors point out that not much is known about the function of frequencies above $30 \mathrm{~Hz}$; particularly due to vastly different neural architecture, it remains unclear whether or not the function of cerebellar gamma band activity could be similar to its role in cerebral cortex.

What might be the generating mechanisms of higherfrequency cerebellar LFP activity?

Purkinje cells are tonically active, exhibiting ongoing spontaneous discharges that may be modulated by incoming stimuli or efferent motor actions (Ito, 2006). For example, monkey Purkinje cells are known to spike at high frequencies, from $70 \mathrm{~Hz}$ at rest up to several hundred Hertz during a task (Thach, 1968). It may be reasonable to expect, therefore, that modulations of the firing rate could result in both increases and decreases of oscillatory activity in several frequency bands depending on a variety of factors, most of all the level of synchrony across local populations. 


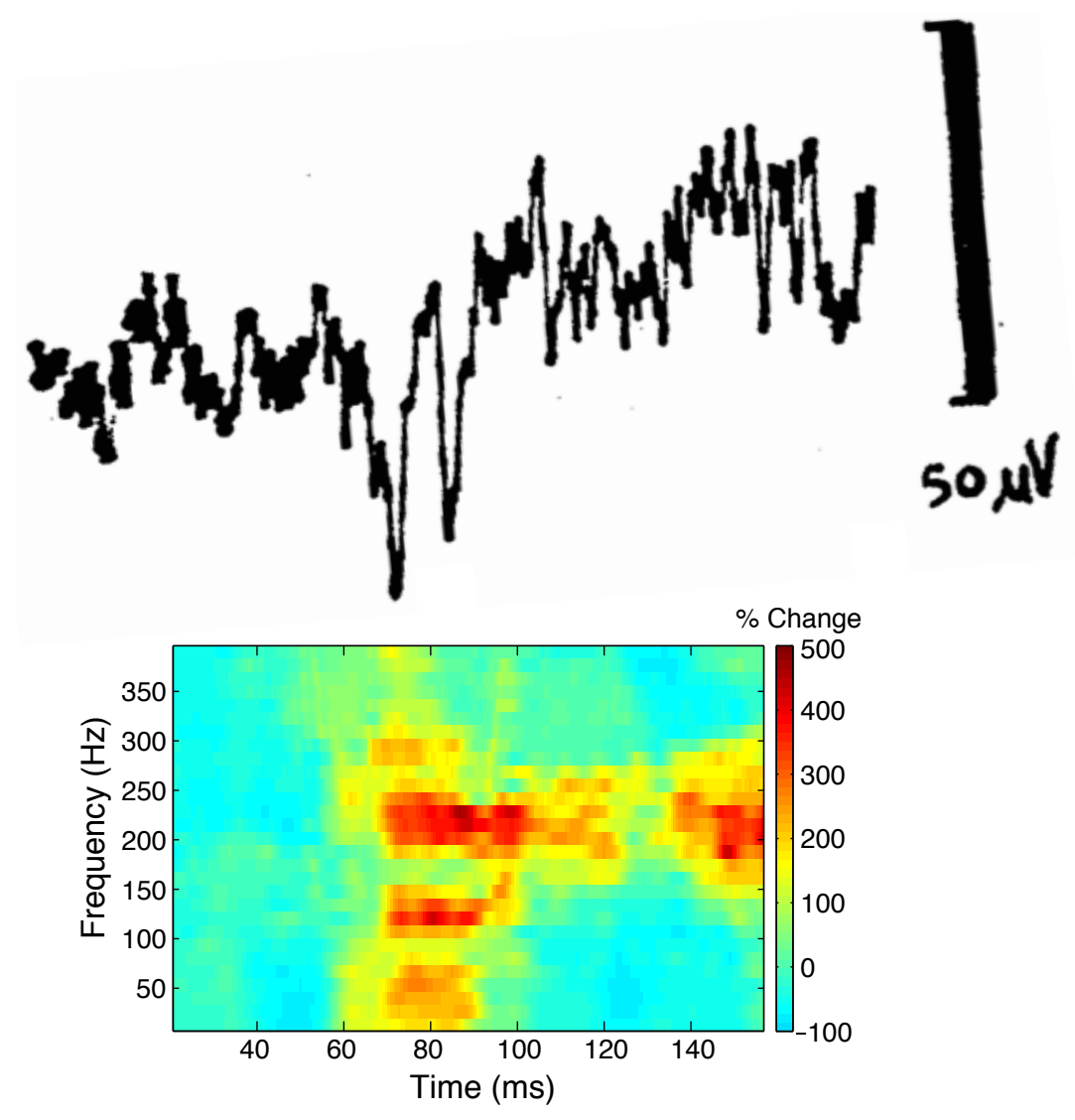

Figure 4: At top, a spontaneous recording from the surface of the posterior vermis from a human patient, from Rétif (1964, Figure 4), reproduced with permission. Rétif speculates that the prominent wave between 70-90 ms had been evoked by sensory stimulation. At bottom, the spectrogram normalized with respect to the period before the large wave, 0-50 ms, expressed as percent change in power. Note the prominent sustained increase in power between $200-300 \mathrm{~Hz}$, as well as more transient effects at lower frequencies.

Complex spikes are a peculiar phenomenon that arise in Purkinje cells, and take the form of a large initial spike followed by a rapid train of lower-amplitude action potentials (de Zeeuw et al., 2011). Input from climbing fibers, which arise from the inferior olivary nucleus and synapse on multiple Purkinje cells, appear to drive production of complex spikes. Climbing fibers can activate in synchrony (Welsh, 2002) and generate oscillations in the alpha range (Lang et al., 2006). More recent findings suggest that they may also generate high-frequency bursts (Mathy et al., 2009). Parasagittal bands of Purkinje cells are consequently capable of producing synchronous complex spikes in response to climbing fiber input (Sasaki et al., 1989; Lang et al., 1999).

The granular layer of the cerebellum is known to generate oscillations across the low-frequency range, including sleep slow waves $(1.5-2.5 \mathrm{~Hz})$ in synchrony with cerebral cortex (Rowland et al., 2010) as well as other oscillations up to $25 \mathrm{~Hz}$ (D'Angelo et al., 2009). It is furthermore predicted to produce high-frequency oscillations (D'Angelo et al., 2009). Higher-frequency activity may be generated by the parallel fibers, the long axons which arise from cerebellar granule cells.
Figure 5 depicts these potential mechanisms for large oscillatory generators in cerebellar cortex. Synchrony across different cerebellar neuron populations likely contributes to measurable LFP activity, and a sufficiently large population could conceivably produce extracranially measurable signals.

Armed with this knowledge, we may now consider MEG reports of cerebellar oscillatory modulations with more confidence, and design strategies to better characterize the dynamics of cerebellum activity from noninvasive data in humans.

Ultimately, methodological limitations may have led too hastily to the conclusion that EEG and MEG cannot detect cerebellar sources at the level of the scalp. Many human EEG/MEG studies may simply not have had the proper spatial coverage to capture cerebellar sources; traditional 10/20 EEG electrode placement and even state-ofthe-art high-density electrode caps as well as some wholehead MEG systems could miss the head regions where cerebellar signals might project, e.g., the top of the neck (Hashimoto et al., 2003). Moreover, until recently, it was not common for EEG/MEG to have been acquired with sufficient bandwidth or sampling rate to capture early- 


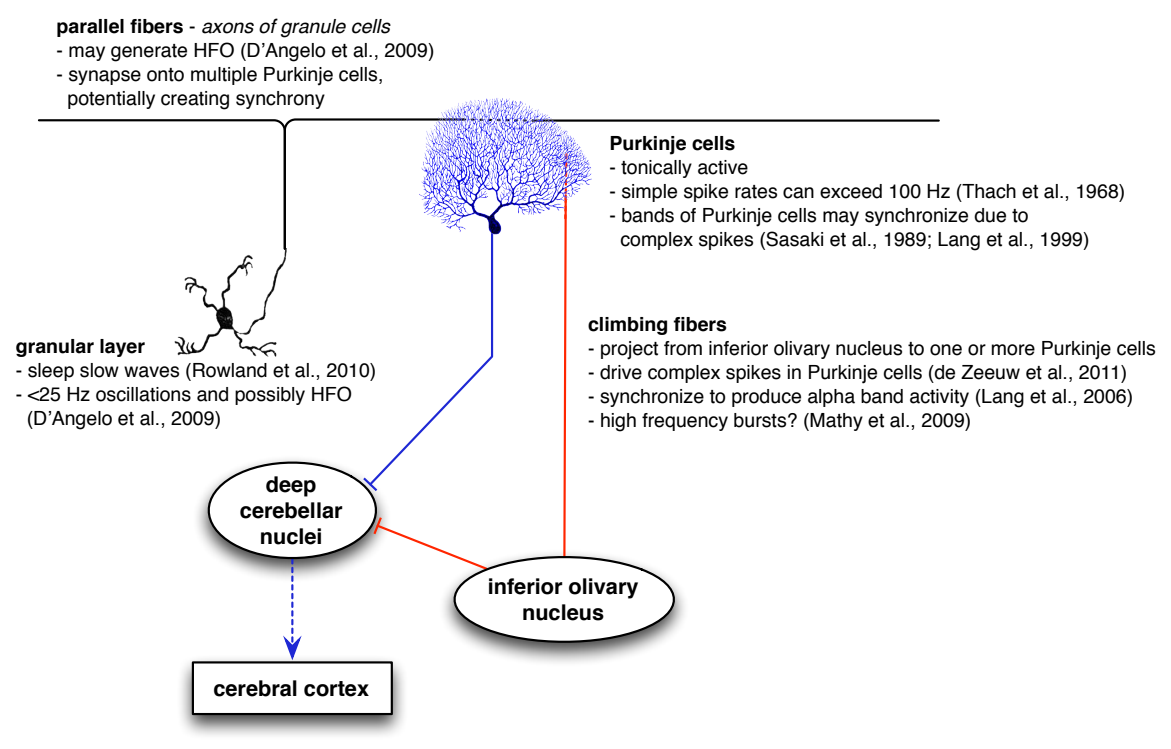

Figure 5: A diagram of cerebellar circuits that may contribute to synchronous oscillatory activity over patches of cerebellar cortex.

latency or high-frequency responses. But even with recording at wider bandwidths, if the cerebellum exhibits modulations in these higher frequency ranges, they may have been easily dismissed as muscular artifact. Conversely, most of the MEG reports to date have either aimed to study motor networks or involved button-press responses, and therefore incidental neck muscle activity could be a potential confound in these studies. With the cerebellum gaining increasing attention for nonmotor functions in recent years (Strick et al., 2009; Stoodley, 2011), perhaps a passive stimulation paradigm can be designed to activate posterior regions of the cerebellum and thereby provide some alternative validation.

As cerebellar responses seem to be of relatively lower amplitude and contain significant higher frequency components, their detection can certainly be aided by, e.g., increasing the number of trials as much as possible as well as artifact rejection or correction (Jerbi et al., 2009).

Lower signal amplitudes from the cerebellum furthermore imply that activity of adjacent occipital cortex may dominate the MEG/EEG traces if no attempt at source localization is made. Yet even source localization may prove unreliable until forward models that specifically account for the cerebellum are developed. MEG analyses traditionally assumed a spherical head model fit to cerebral cortex, perhaps resulting in a poor fit with cerebellar cortex; more recently, implementations of realistic head models still neglect the morphology of the cerebellum, either removing it completely or including it within the same compartment as cerebral cortex. Additionally, techniques that assume sources to be oriented orthogonally to the cortical surface may need refinement for the cerebellum, as the cerebellar surface is less easily segmented from standard-resolution T1 MR images. High-field MRI may help in this endeavor and is already providing exquisite detail of the living hu- man cerebellum (Marques et al., 2010, 2012). Finally, an extension of the dura mater called the tentorium cerebelli separates the cerebellum from the cerebrum and may further influence the conduction of cerebellar signals. Therefore, the cerebellum would ultimately profit from realistic models that specifically take into account its unique electrical properties.

With proper development of these forward models, in combination with a revised expectation of what sorts of signals arise from the cerebellum, robust methods for noninvasive reconstruction of cerebellar dynamics may finally be within reach, providing tools both for neuroscientific study and for neurological diagnostics.

\section{Appendix: Spectral Analysis Methods}

Electrode traces were digitized from scans of the publications with the aid of PlotDigitizer software (http://plotdigitizer.sourceforge.net/).

Spectrograms were subsequently calculated from the digitized data using multitaper analysis functions from the Chronux toolbox (Mitra and Bokil, 2008, http://chronux.org/). Multitaper analysis was chosen due to its robustness in the spectral analysis of short data segments (Mitra and Pesaran, 1999).

For the data from Irger et al. (1949a), a multitaperbased spectrogram was computed by using a window of $300 \mathrm{~ms}$ shifted over the data with a stepsize of $0.5 \mathrm{~ms}$. A bandwidth parameter of $10 \mathrm{~Hz}$ was used with 4 Slepian tapers. The trigger latency was marked on the original figure, and this time point was defined as $t=0$. These spectrograms were then normalized by the average power over the available pre-stimulus interval from -730 to $0 \mathrm{~ms}$.

The electrode trace from Rétif (1964) portrays a shorter recording made with a CRT oscilloscope, and 
therefore was able to capture higher frequencies. Accordingly, different spectrogram parameters were used. A sliding window of $40 \mathrm{~ms}$ was employed with a stepsize of $0.5 \mathrm{~ms}$, using 4 Slepian tapers and a bandwidth parameter of $75 \mathrm{~Hz}$. The spectrogram was normalized by the first $50 \mathrm{~ms}$ of the recording, which was assumed to be prior to the stimulus. As the trigger latency was not recorded, $t=0$ was defined as the beginning of the data segment.

\section{Acknowledgments}

The authors would like to thank Ryan T. Canolty for retrieving Irger et al. (1951) from the archives of the UC Berkeley Moffitt Library, and the Library of the University of Konstanz for locating the other materials.

\section{References}

Adrian, E. D., 1935. Discharge frequencies in the cerebral and cerebellar cortex. J Physiol 83 (Suppl), 32P-33P.

Axmacher, N., Schmitz, D. P., Wagner, T., Elger, C. E., Fell, J., 2008. Interactions between medial temporal lobe, prefrontal cortex, and inferior temporal regions during visual working memory: a combined intracranial EEG and functional magnetic resonance imaging study. J Neurosci 28, 7304-7312.

Ball, T., Demandt, E., Mutschler, I., Neitzel, E., Mehring, C., Vogt, K., Aertsen, A., Schulze-Bonhage, A., 2008. Movement related activity in the high gamma range of the human EEG. NeuroImage 41, 302-310.

Belardinelli, P., Ciancetta, L., Staudt, M., Pizzella, V., Londei, A., Birbaumer, N., Romani, G. L., Braun, C., 2007. Cerebro-muscular and cerebro-cerebral coherence in patients with pre- and perinatally acquired unilateral brain lesions. NeuroImage 37, 1301-1314.

Bourguignon, M., De Tiège, X., de Beeck, M. O., Van Bogaert, P., Goldman, S., Jousmäki, V., Hari, R., 2013. Primary motor cortex and cerebellum are coupled with the kinematics of observed hand movements. NeuroImage 66, 500-507.

Brookes, M. J., Woolrich, M., Luckhoo, H., Price, D., Hale, J. R., Stephenson, M. C., Barnes, G. R., Smith, S. M., Morris, P. G., 2011. Investigating the electrophysiological basis of resting state networks using magnetoencephalography. Proc Natl Acad Sci USA 108, 16783-16788.

Brookhart, J. M., Moruzzi, G., Snider, R. S., 1950. Spike discharges of single units in the cerebellar cortex. J Neurophysiol 13, 465-486.

Brookhart, J. M., Moruzzi, G., Snider, R. S., 1951. Origin of cerebellar waves. J Neurophysiol 14, 181-190.

Butz, M., Timmermann, L., Gross, J., Pollok, B., Dirks, M., Hefter, H., Schnitzler, A., 2006. Oscillatory coupling in writing and writer's cramp. J Physiol Paris 99, 14-20.

Canolty, R. T., Edwards, E., Dalal, S. S., Soltani, M., Nagarajan, S. S., Kirsch, H. E., Berger, M. S., Barbaro, N. M., Knight, R. T., 2006. High Gamma Power Is Phase-Locked to Theta Oscillations in Human Neocortex. Science 313, 1626-1628.

Canolty, R. T., Knight, R. T., 2010. The functional role of crossfrequency coupling. Trends Cogn Sci 14, 506-515.

Chae, J. H., Kim, S. K., Wang, K. C., Kim, K. J., Hwang, Y. S., Cho, B. K., 2001. Hemifacial seizure of cerebellar ganglioglioma origin: seizure control by tumor resection. Epilepsia 42, 1204-1207.

Chang, E. F., Edwards, E., Nagarajan, S. S., Fogelson, N., Dalal, S. S., Canolty, R. T., Kirsch, H. E., Barbaro, N. M., Knight, R. T., 2011. Cortical spatio-temporal dynamics underlying phonological target detection in humans. J Cogn Neurosci 23, 1437-1446.

Cornwell, B. R., Baas, J. M. P., Johnson, L., Holroyd, T., Carver, F. W., Lissek, S., Grillon, C., 2007. Neural responses to auditory stimulus deviance under threat of electric shock revealed by spatially-filtered magnetoencephalography. NeuroImage 37, 282289.
Crone, N. E., Korzeniewska, A., Franaszczuk, P. J., 2011. Cortical gamma responses: Searching high and low. Int J Psychophysiol $79,9-15$.

Crone, N. E., Miglioretti, D. L., Gordon, B., Lesser, R. P., 1998. Functional mapping of human sensorimotor cortex with electrocorticographic spectral analysis. II. Event-related synchronization in the gamma band. Brain 121, 2301-2315.

Dalal, S. S., Baillet, S., Adam, C., Ducorps, A., Schwartz, D., Jerbi, K., Bertrand, O., Garnero, L., Martinerie, J., Lachaux, J.-P., 2009. Simultaneous MEG and intracranial EEG recordings during attentive reading. NeuroImage 45, 1289-1304.

Dalal, S. S., Guggisberg, A. G., Edwards, E., Sekihara, K., Findlay, A. M., Canolty, R. T., Berger, M. S., Knight, R. T., Barbaro, N. M., Kirsch, H. E., Nagarajan, S. S., 2008. Five-dimensional neuroimaging: localization of the time-frequency dynamics of cortical activity. NeuroImage 40, 1686-1700.

D'Angelo, E., Koekkoek, S. K. E., Lombardo, P., Solinas, S., Ros, E., Garrido, J., Schonewille, M., de Zeeuw, C. I., 2009. Timing in the cerebellum: oscillations and resonance in the granular layer. Neuroscience 162, 805-815.

de Solages, C., Szapiro, G., Brunel, N., Hakim, V., Isope, P., Buisseret, P., Rousseau, C., Barbour, B., Léna, C., 2008. Highfrequency organization and synchrony of activity in the Purkinje cell layer of the cerebellum. Neuron 58, 775-788.

de Zeeuw, C. I., Hoebeek, F. E., Bosman, L. W. J., Schonewille, M., Witter, L., Koekkoek, S. K., 2011. Spatiotemporal firing patterns in the cerebellum. Nat Rev Neurosci 12, 327-344.

de Zeeuw, C. I., Hoebeek, F. E., Schonewille, M., 2008. Causes and consequences of oscillations in the cerebellar cortex. Neuron 58, $655-658$.

Delande, O., Rodriguez, D., Chiron, C., Fohlen, M., 2001. Successful surgical relief of seizures associated with hamartoma of the floor of the fourth ventricle in children: report of two cases. Neurosurgery 49, 726-30; discussion 730-1.

Diedrichsen, J., Verstynen, T., Schlerf, J., Wiestler, T., 2010. Advances in functional imaging of the human cerebellum. Curr Opin Neurol 23, 382-387.

Dow, R. S., 1938. The electrical activity of the cerebellum and its functional significance. J Physiol (Lond) 94, 67-86.

Eccles, J. C., Llinás, R., Sasaki, K., 1966a. The action of antidromic impulses on the cerebellar Purkinje cells. J Physiol (Lond) 182, 316-345.

Eccles, J. C., Llinás, R., Sasaki, K., 1966b. The excitatory synaptic action of climbing fibres on the Purkinje cells of the cerebellum. J Physiol (Lond) 182, 268-296.

Edwards, E., Soltani, M., Kim, W., Dalal, S. S., Nagarajan, S. S., Berger, M. S., Knight, R. T., 2009. Comparison of time-frequency responses and the event-related potential to auditory speech stimuli in human cortex. J Neurophysiol 102, 377-86.

Flinker, A., Chang, E. F., Kirsch, H. E., Barbaro, N. M., Crone, N. E., Knight, R. T., 2010. Single-trial speech suppression of auditory cortex activity in humans. J Neurosci 30, 16643-16650.

Foerster, O., Altenburger, H., 1935. Elektrobiologische Vorgänge an der menschlichen Hirnrinde. Deutsche Zeitschrift für Nervenheilkunde 135, 277-288.

Fuchs, A. F., Kornhuber, H. H., 1969. Extraocular muscle afferents to the cerebellum of the cat. J Physiol (Lond) 200, 713-722.

Fujioka, T., Trainor, L. J., Large, E. W., Ross, B., 2012. Internalized timing of isochronous sounds is represented in neuromagnetic oscillations. J Neurosci 32, 1791-1802.

Gerloff, C., Altenmuller, E., Dichgans, J., 1996. Disintegration and reorganization of cortical motor processing in two patients with cerebellar stroke. Electroencephalogr Clin Neurophysiol 98, 59-68.

Glickstein, M., Sultan, F., Voogd, J., 2011. Functional localization in the cerebellum. Cortex 47, 59-80.

Grimaldi, G., Manto, M., 2012. Topography of cerebellar deficits in humans. Cerebellum 11, 336-351.

Gross, J., Timmermann, L., Kujala, J., Dirks, M., Schmitz, F., Salmelin, R., Schnitzler, A., 2002. The neural basis of intermittent motor control in humans. Proc Natl Acad Sci U S A 99, 2299-2302. 
Guggisberg, A. G., Dalal, S. S., Findlay, A. M., Nagarajan, S. S. 2007. High-frequency oscillations in distributed neural networks reveal the dynamics of human decision making. Front Hum Neurosci 1,14 .

Guggisberg, A. G., Dalal, S. S., Schnider, A., Nagarajan, S. S., 2011. The neural basis of event-time introspection. Conscious Cogn 20, 1899-1915

Gupta, V., Garg, A., Chandra, S., Sharma, M., Gaikwad, S., Gulati, S., Mishra, N., 2003. Cerebellar epilepsy. Rivista di Neuroradiologia $16,784-787$

Harvey, A. S., Jayakar, P., Duchowny, M., Resnick, T., Prats, A., Altman, N., Renfroe, J. B., 1996. Hemifacial seizures and cerebellar ganglioglioma: an epilepsy syndrome of infancy with seizures of cerebellar origin. Ann Neurol 40, 91-98.

Hashimoto, I., Kimura, T., Tanosaki, M., Iguchi, Y., Sekihara, K. 2003. Muscle afferent inputs from the hand activate human cerebellum sequentially through parallel and climbing fiber systems. Clin Neurophysiol 114, 2107-2117.

Heath, R. G., 1972a. Marihuana. Effects on deep and surface electroencephalograms of man. Arch Gen Psychiatry 26, 577-584.

Heath, R. G., 1972b. Pleasure and brain activity in man. Deep and surface electroencephalograms during orgasm. J Nerv Ment Dis 154, 3-18.

Heath, R. G., Cox, A. W., Lustick, L. S., 1974. Brain activity during emotional states. Am J Psychiatry 131, 858-862.

Hoogenboom, N., Schoffelen, J.-M., Oostenveld, R., Parkes, L. M., Fries, P., 2006. Localizing human visual gamma-band activity in frequency, time and space. NeuroImage 29, 764-773.

Houck, J., Martin, T., Bish, J., Moses, S., Woodruff, C., Kičić, D., Tesche, C., 2007. Early cerebellar activation predicts response time. International Congress Series 1300, 413-416.

Ioannides, A. A., Fenwick, P. B. C., 2005. Imaging cerebellum activity in real time with magnetoencephalographic data. Prog Brain Res 148, 139-150.

Ioannides, A. A., Fenwick, P. B. C., Liu, L., 2005. Widely distributed magnetoencephalography spikes related to the planning and execution of human saccades. J Neurosci 25, 7950-7967.

Irger, I. M., Koreisha, L. A., Tolmasskaia, E. S., 1949a. [Electric potentials of the human cerebellum]. Voprosy Nejrochirurgii 5 , 34-38.

Irger, I. M., Koreisha, L. A., Tolmasskaia, E. S., 1949b. [On spontaneous biolelectrical activity of the human cerebellum]. Biulleten èksperimentalnoŭ biologii i meditsiny 27, 257-260.

Irger, I. M., Koreisha, L. A., Tolmasskaia, E. S., 1951. [Investigation on the electric activity of phylogenetically different segments of the cerebellum in man and animal]. Fiziologicheskiǔ zhurnal SSSR imeni I. M. Sechenova 37, 273-282.

Isope, P., Dieudonné, S., Barbour, B., 2002. Temporal organization of activity in the cerebellar cortex: a manifesto for synchrony. Ann N Y Acad Sci 978, 164-174.

Ito, M., 2006. Cerebellar circuitry as a neuronal machine. Prog Neurobiol $78,272-303$.

Jacobs, J., Zijlmans, M., Zelmann, R., Chatillon, C.-E., Hall, J., Olivier, A., Dubeau, F., Gotman, J., 2010. High-frequency electroencephalographic oscillations correlate with outcome of epilepsy surgery. Ann Neurol 67, 209-220.

Jensen, O., Kaiser, J., Lachaux, J.-P., 2007. Human gammafrequency oscillations associated with attention and memory. Trends Neurosci 30, 317-324.

Jerbi, K., Lachaux, J.-P., N'Diaye, K., Pantazis, D., Leahy, R. M. Garnero, L., Baillet, S., 2007. Coherent neural representation of hand speed in humans revealed by MEG imaging. Proc Natl Acad Sci USA 104, 7676-7681.

Jerbi, K., Ossandón, T., Hamamé, C. M., Senova, S., Dalal, S. S., Jung, J., Minotti, L., Bertrand, O., Berthoz, A., Kahane, P., Lachaux, J.-P., 2009. Task-related gamma-band dynamics from an intracerebral perspective: review and implications for surface EEG and MEG. Hum Brain Mapp 30, 1758-71.

Jousmäki, V., Hämäläinen, M., Hari, R., 1996. Magnetic source imaging during a visually guided task. NeuroReport 7, 2961-2964.

Kennedy, J. S., Singh, K. D., Muthukumaraswamy, S. D., 2011. An
MEG investigation of the neural mechanisms subserving complex visuomotor coordination. Int J Psychophysiol 79, 296-304.

Koh, K. N., Lim, B. C., Hwang, H., Park, J. D., Chae, J. H., Kim, K. J., Hwang, Y.-S., Kim, S.-K., Wang, K.-C., Moon, H. K., 2010. Cerebellum can be a possible generator of progressive myoclonus. J Child Neurol 25, 728-731.

Kotini, A., Mavraki, E., Anninos, P., Piperidou, H., Prassopoulos, P., 2010. Magnetoencephalographic findings in two cases of juvenile myoclonus epilepsy. Brain Topogr 23, 41-45.

Krause, V., Schnitzler, A., Pollok, B., 2010. Functional network interactions during sensorimotor synchronization in musicians and non-musicians. NeuroImage 52, 245-251.

Kujala, J., Pammer, K., Cornelissen, P., Roebroeck, A., Formisano, E., Salmelin, R., 2007. Phase coupling in a cerebro-cerebellar network at 8-13 Hz during reading. Cereb Cortex 17, 1476-1485.

Kwan, H. C., Murphy, J. T., 1974a. Extracellular current density analysis of responses in cerebellar cortex to climbing fiber activation. J Neurophysiol 37, 333-345.

Kwan, H. C., Murphy, J. T., 1974b. Extracellular current density analysis of responses in cerebellar cortex to mossy fiber activation. J Neurophysiol 37, 947-953.

Lachaux, J.-P., Jerbi, K., Bertrand, O., Minotti, L., Hoffmann, D., Schoendorff, B., Kahane, P., 2007. BrainTV: a novel approach for online mapping of human brain functions. Biol Res 40, 401-413.

Lachaux, J. P., Rodriguez, E., Martinerie, J., Adam, C., Hasboun, D., Varela, F. J., 2000. A quantitative study of gamma-band activity in human intracranial recordings triggered by visual stimuli. Eur J Neurosci 12, 2608-2622.

Lalo, E., Thobois, S., Sharott, A., Polo, G., Mertens, P., Pogosyan, A., Brown, P., 2008. Patterns of bidirectional communication between cortex and basal ganglia during movement in patients with Parkinson disease. J Neurosci 28, 3008-3016.

Lang, E. J., Sugihara, I., Llinás, R., 2006. Olivocerebellar modulation of motor cortex ability to generate vibrissal movements in rat. J Physiol (Lond) 571, 101-120.

Lang, E. J., Sugihara, I., Welsh, J. P., Llinás, R., 1999. Patterns of spontaneous purkinje cell complex spike activity in the awake rat. J Neurosci 19, 2728-2739.

Lascano, A. M., Lemkaddem, A., Granziera, C., Korff, C. M., Boex, C., Jenny, B., Schmitt-Mechelke, T., Thiran, J.-P., Garibotto, V., Vargas, M. I., Schaller, K., Seeck, M., Vulliemoz, S., in press. Tracking the source of cerebellar epilepsy: Hemifacial seizures associated with cerebellar cortical dysplasia. Epilepsy Res.

Marques, J. P., Gruetter, R., van der Zwaag, W., 2012. In vivo structural imaging of the cerebellum, the contribution of ultrahigh fields. Cerebellum 11, 384-391.

Marques, J. P., van der Zwaag, W., Granziera, C., Krueger, G., Gruetter, R., 2010. Cerebellar cortical layers: in vivo visualization with structural high-field-strength MR imaging. Radiology 254, 942-948.

Martin, T., Houck, J. M., Bish, J. P., Kicić, D., Woodruff, C. C., Moses, S. N., Lee, D. C., Tesche, C. D., 2006. MEG reveals different contributions of somatomotor cortex and cerebellum to simple reaction time after temporally structured cues. Hum Brain Mapp $27,552-561$.

Mathy, A., Ho, S. S. N., Davie, J. T., Duguid, I. C., Clark, B. A., Häusser, M., 2009. Encoding of oscillations by axonal bursts in inferior olive neurons. Neuron 62, 388-399.

Mesiwala, A. H., Kuratani, J. D., Avellino, A. M., Roberts, T. S., Sotero, M. A., Ellenbogen, R. G., 2002. Focal motor seizures with secondary generalization arising in the cerebellum. Case report and review of the literature. J Neurosurg 97, 190-196.

Middleton, S. J., Racca, C., Cunningham, M. O., Traub, R. D., Monyer, H., Knöpfel, T., Schofield, I. S., Jenkins, A., Whittington, M. A., 2008. High-frequency network oscillations in cerebellar cortex. Neuron 58, 763-774.

Mitra, P., Bokil, H., 2008. Observed Brain Dynamics. Oxford University Press, Oxford.

Mitra, P. P., Pesaran, B., 1999. Analysis of dynamic brain imaging data. Biophys J 76, 691-708.

Mohamed, I. S., Otsubo, H., Ferrari, P., Ochi, A., Snead, O. C., 
Cheyne, D., 2011. Neuromagnetic cerebellar activation during seizures arising from the motor cortex. Epilepsy Res 96, 283-287. Muthukumaraswamy, S. D., Johnson, B. W., Gaetz, W. C., Cheyne, D. O., 2006. Neural processing of observed oro-facial movements reflects multiple action encoding strategies in the human brain. Brain Res 1071, 105-112.

Muthukumaraswamy, S. D., Johnson, B. W., Hamm, J. P., 2003. A high density ERP comparison of mental rotation and mental size transformation. Brain Cogn 52, 271-280.

Nicholson, C., Llinas, R., 1971. Field potentials in the alligator cerebellum and theory of their relationship to Purkinje cell dendritic spikes. J Neurophysiol 34, 509-531.

Niedermeyer, E., 2004. The electrocerebellogram. Clin EEG Neurosci $35,112-115$.

Niedermeyer, E., da Silva, F., 2005. Electroencephalography: Basic Principles, Clinical Applications, and Related Fields. Lippincott Williams \& Wilkins, Philadelphia, PA, USA.

Niedermeyer, E., Uematsu, S., 1974. Electroencephalographic recordings from deep cerebellar structures in patients with uncontrolled epileptic seizures. Electroencephalogr Clin Neurophysiol $37,355-365$

Okada, Y. C., Lauritzen, M., Nicholson, C., 1987. Magnetic field associated with neural activities in an isolated cerebellum. Brain Res 412, 151-155.

Osipova, D., Hermes, D., Jensen, O., 2008. Gamma power is phaselocked to posterior alpha activity. PLoS ONE 3, e3990.

Ossandón, T., Vidal, J. R., Ciumas, C., Jerbi, K., Hamamé, C. M. Dalal, S. S., Bertrand, O., Minotti, L., Kahane, P., Lachaux, J.-P. 2012. Efficient "pop-out" visual search elicits sustained broadband gamma activity in the dorsal attention network. J Neurosci 32, 3414-3421.

Parvizi, J., 2009. Corticocentric myopia: old bias in new cognitive sciences. Trends Cogn Sci 13, 354-359.

Pellet, J., 1967. L'électrocérébellogramme vermien au cours des états de veille et de sommeil. Brain Res 5, 266-270.

Pollok, B., Butz, M., Gross, J., Schnitzler, A., 2007. Intercerebellar coupling contributes to bimanual coordination. J Cogn Neurosci 19, 704-719.

Pollok, B., Gross, J., Müller, K., Aschersleben, G., Schnitzler, A., 2005. The cerebral oscillatory network associated with auditorily paced finger movements. NeuroImage 24, 646-655.

Ramón y Cajal, S., 1904. Textura del Sistema Nervioso del Hombre y de los Vertebrados. N. Moya, Madrid.

Rétif, J., 1964. Étude de l'activité électrique spontanée du cervelet humain. Acta Neurol Psychiatr Belg 64, 825-831.

Rowland, N. C., Goldberg, J. A., Jaeger, D., 2010. Cortico-cerebellar coherence and causal connectivity during slow-wave activity. Neuroscience 166, 698-711.

Rowland, N. C., Jaeger, D., 2008. Responses to tactile stimulation in deep cerebellar nucleus neurons result from recurrent activation in multiple pathways. J Neurophysiol 99, 704-717.

Sasaki, K., Bower, J. M., Llinás, R., 1989. Multiple Purkinje cell recording in rodent cerebellar cortex. Eur J Neurosci 1, 572-586.

Schmahmann, J. D., Weilburg, J. B., Sherman, J. C., 2007. The neuropsychiatry of the cerebellum - insights from the clinic. Cerebellum 6, 254-267.

Schnitzler, A., Münks, C., Butz, M., Timmermann, L., Gross, J., 2009. Synchronized brain network associated with essential tremor as revealed by magnetoencephalography. Mov Disord 24, 16291635 .

Schwartz, H. G., Kerr, A. S., 1940. Electrical activity of the exposed human brain: description of technic and report of observations. Arch Neurol Psychiatry 43, 547-558.

Sem-Jacobsen, C. W., Petersen, M. C., Lazarte, J. A., Dodge, H. W., Holman, C. B., 1955. Intracerebral and intracerebellar electrography in Huntington's chorea. Proc Staff Meet Mayo Clin 30, 365370.

Snider, R., Stowell, A., 1944. Receiving areas of the tactile, auditory, and visual systems in the cerebellum. J Neurophysiol 7, 331-357.

Stoodley, C. J., 2011. The Cerebellum and Cognition: Evidence from Functional Imaging Studies. Cerebellum.
Stoodley, C. J., Schmahmann, J. D., 2009. Functional topography in the human cerebellum: A meta-analysis of neuroimaging studies. NeuroImage 44, 489-501.

Strick, P. L., Dum, R. P., Fiez, J. A., 2009. Cerebellum and nonmotor function. Annu Rev Neurosci 32, 413-434.

Tass, P. A., Fieseler, T., Dammers, J., Dolan, K., Morosan, P., Majtanik, M., Boers, F., Muren, A., Zilles, K., Fink, G. R., 2003. Synchronization tomography: a method for three-dimensional localization of phase synchronized neuronal populations in the human brain using magnetoencephalography. Phys Rev Lett 90, 088101.

ten Cate, J., Wiggers, N., 1942. On the occurrence of slow waves in the electrocerebellogram. Arch Neerl Physiol l'Homme Anim 26, 433-435.

Tesche, C., Moses, S., Houck, J., Martin, T., Hanlon, F., 2007. Dynamics of frontal and cerebellar activation during aversive conditioning: An MEG study. International Congress Series.

Tesche, C. D., Karhu, J., 1997. Somatosensory evoked magnetic fields arising from sources in the human cerebellum. Brain Res 744, 2331.

Tesche, C. D., Karhu, J. J., 2000. Anticipatory cerebellar responses during somatosensory omission in man. Hum Brain Mapp 9, 119 142 .

Thach, W. T., 1968. Discharge of Purkinje and cerebellar nuclear neurons during rapidly alternating arm movements in the monkey. J Neurophysiol 31, 785-797.

Timmermann, L., Gross, J., Butz, M., Kircheis, G., Haussinger, D. Schnitzler, A., 2004. Pathological oscillatory coupling within the human motor system in different tremor syndromes as revealed by magnetoencephalography. Neurol Clin Neurophysiol 2004, 26.

Timmermann, L., Gross, J., Dirks, M., Volkmann, J., Freund, H.-J., Schnitzler, A., 2003. The cerebral oscillatory network of parkinsonian resting tremor. Brain 126, 199-212.

VanGilder, J. C., O’Leary, J. L., Ferguson, J. P., 1967. Steady potential of cerebellar cortex. Results of direct, olivo- and pontocerebellar activation. Electroencephalogr Clin Neurophysiol 22, 401-413.

Vidal, J. R., Ossandón, T., Jerbi, K., Dalal, S. S., Minotti, L., Ryvlin, P., Kahane, P., Lachaux, J.-P., 2010. Category-Specific Visual Responses: An Intracranial Study Comparing Gamma, Beta, Alpha, and ERP Response Selectivity. Front Hum Neurosci 4, 195 .

Welsh, J. P., 2002. Functional significance of climbing-fiber synchrony: a population coding and behavioral analysis. Ann N Y Acad Sci 978, 188-204.

Wibral, M., Rahm, B., Rieder, M., Lindner, M., Vicente, R., Kaiser, J., 2011. Transfer entropy in magnetoencephalographic data: quantifying information flow in cortical and cerebellar networks. Prog Biophys Mol Biol 105, 80-97.

Wilson, T. W., Slason, E., Asherin, R., Kronberg, E., Reite, M. L., Teale, P. D., Rojas, D. C., 2010. An extended motor network generates beta and gamma oscillatory perturbations during development. Brain Cogn 73, 75-84.

Wilson, T. W., Slason, E., Asherin, R., Kronberg, E., Teale, P. D., Reite, M. L., Rojas, D. C., 2011. Abnormal Gamma and Beta MEG Activity During Finger Movements in Early-Onset Psychosis. Dev Neuropsychol 36, 596-613.

Wilson, T. W., Slason, E., Hernandez, O. O., Asherin, R., Reite, M. L., Teale, P. D., Rojas, D. C., 2009. Aberrant high-frequency desynchronization of cerebellar cortices in early-onset psychosis. Psychiatry Res 174, 47-56.

Worrell, G. A., Jerbi, K., Kobayashi, K., Lina, J. M., Zelmann, R., Le Van Quyen, M., 2012. Recording and analysis techniques for high-frequency oscillations. Prog Neurobiol 98, 265-278.

Yagyu, K., Sueda, K., Shiraishi, H., Asahina, N., Sakurai, K., Kohsaka, S., Sawamura, Y., Saitoh, S., 2011. Direct correlation between the facial nerve nucleus and hemifacial seizures associated with a gangliocytoma of the floor of the fourth ventricle: a case report. Epilepsia 52, e204-6. 